\title{
Aspectos políticos da tragédia grega: a importância do concurso e do mito*
}

Resumo: A partir das interpretações de Jean-Pierre Vernant e Christian Meier sobre o espetáculo trágico, destacam-se neste artigo os aspectos políticos da tragédia grega, mostrando como o texto trágico grego é um fenômeno social ligado a uma concepção grega sobre o fazer político. Assim são evidenciados o teatro como um festa em homenagem ao deus Dionisio, congregadora de aspectos identitários, a importância do coro e a relação entre mito e tragédia.

Palavras-chave: Tragédia Grega; Mito; Política.

Abstract: Political aspects of Greek tragedy as well as its relation with myth are explored in light of Jean-Pierre Vernant's and Christian Meier's interpretations, aiming to characterize Greek tragedy as a social phenomenon linked to certain notions about political affairs. Greek theather is analyzed as a festival in homage to Dionysus which dealt with identity issues and political questions.

Keywords: Greek Tragedy; Myth; Politics.

Desde a Poética de Aristóteles escrita no século IV a.C muito se tem discutido sobre os aspectos formais de uma tragédia grega e a partir do romantismo alemão no século XVIII começou-se a pensar uma filosofia do trágico. Apesar de levantar importantes problemas, as discussões estéticas e filosóficas esquecem uma outra abordagem do texto trágico grego, preocupada em entender a tragédia, ou o teatro trágico, como um fenômeno social grego do século V a.C.

O objetivo desse artigo é mostrar como a tragédia grega é concebida dentro de uma esfera social específica, com o intuito de discutir problemas de ordem pública na esfera política. Para isso, são abordadas principalmente as ideias do helenista francês Jean-Pierre Vernant e do alemão Christian Meier. Cabe ressaltar aqui a singularidade do texto trágico em seus sentidos políticos na relação que a tragédia estabelecia entre autor-pólis-cidadão.

Roland Barthes discute no artigo "Pouvoir de la tragédie antique" (2002) algumas

\footnotetext{
* Artigo submetido em 05 de novembro de 2012 e aceito para publicação em 09 de janeiro de 2013.

${ }^{1}$ Mestre em História pela UFRGS, com a dissertação "Neoptólemo entre a cicatriz e a chaga: lógos sofistico, peithó e areté na tragédia Filoctetes de Sófocles." Especialização em andamento em Estudos Clássicos pela Cátedra UNESCO Archai. Email: mateusdagios@yahoo.com.br
} 
diferenças entre a tragédia grega e os textos dramáticos produzidos na modernidade. Para o filósofo francês, atento às sensibilidades do teatro, a diferença mais marcante é a dimensão cívica do texto grego: "É quase desnecessário fazer notar [que] o teatro perde toda dimensão cívica. A Cidade está quase sempre ausente da nossa cena.” (BARTHES, 2002: 44) Esta observação serve como ponto de partida para estabelecer a singularidade da tragédia grega. Para compreendermos a relação entre cidadão e teatro, deve-se deslocar o antigo problema das origens da tragédia para o que Jean-Pierre Vernant chamou de os antecedentes do texto trágico. De acordo com o helenista francês, o problema das origens é um falso problema, pois não ajuda a compreender a tragédia mediante abordagens históricas (VERNANT; VIDALNAQUET, 1999). Entretanto, certos aspectos das origens ajudam a compreender o espetáculo trágico.

\section{Festa e concurso para Dioniso}

Concorda-se que a tragédia surgiu no final do século VII a.C. na região de Corinto ou na região de Sícion no Peloponeso. De acordo com a Poética de Aristóteles (1449a), a tragédia nasceu de improvisações a partir do ditirambo, em honra ao deus Dioniso. Thespis, um poeta lírico, teria introduzido o ditirambo na Ática por volta de 550 a.C. em suas apresentações de cidade em cidade. De acordo com Dabdab Trabulsi, a etimologia de tragoédia, canto dos tragodói, recebeu várias explicações: canto de figuras fantasiadas de bode, canto num concurso cujo prêmio era um bode e canto que acompanha o sacrifício de um bode. Mesmo estas tentativas de explicação colocariam "um problema incontornável das origens religiosas, pois é verdade que o teatro grego é o resultado final da passagem de um ritual espetacular a um espetáculo ritual.” (TRABULSI, 2004: 142)

As tragédias eram encenadas em um contexto institucional, inserindo-se no calendário festivo da cidade e tendo lugar e público específicos. Ocorriam nas três festas em homenagem ao deus Dioniso: as Lenéias, que aconteciam no final de janeiro, para as quais se interrompiam os trabalhos do campo, do comércio e da navegação de forma que os cidadãos se dedicassem exclusivamente às festividades; as Grandes Dionisíacas, que aconteciam no final de março e traziam grande número de viajantes para Atenas; as Dionisíacas rurais, que aconteciam em dezembro em regiões da Ática (CUSSET, 1997: 12-3). No edifício do teatro 
consagrado a Dioniso, era reservado um lugar para um templo do deus contendo uma imagem sua; no centro da orkhéstra, havia um altar de pedra em sua homenagem; e nas arquibancadas, um trono esculpido era reservado ao sacerdote de Dioniso (VERNANT; VIDAL-NAQUET, 1999: 158).

Cabem aqui algumas considerações sobre Dioniso e o teatro, pois para Vernant o seu lugar como patrono do teatro causaria em um primeiro momento um estranhamento que exigiria explicações. Este estranhamento está baseado no problema de um teatro que no século $\mathrm{V}$ dialoga com a assembléia e com questões do direito ter um patrono que é o deus do esquecimento, da embriaguez e da alienação. É preciso ter em mente o que Dioniso encarnava: a busca de uma loucura divina, a desmedida, a ausência de limites, a evasão para um horizonte diferente e um desterro radical de si mesmo. A resposta de Vernant parte da ideia de que a tragédia abriu, na cultura grega, "um novo espaço, o do imaginário, sentido e compreendido como tal, isto é: como uma obra humana decorrente do puro artifício" (VERNANT; VIDAL-NAQUET, 1999: 162) -um espaço delineado pela consciência da ficção que permite o distanciamento e a compreensão. Seria esta relação com o ilusório e com o distanciamento que aproximaria a tragédia de um Dioniso que consistiria em "misturar incessantemente as fronteiras do ilusório e do real, em fazer surgir bruscamente o Além aqui embaixo, em nos desprender e nos desterrar de nós mesmos." (VERNANT; VIDALNAQUET, 1999: 162)

Para Meier, as festividades em honra a Dioniso serviam para conciliar aspectos políticos e identitários da pólis:

Certamente, há também razões táticas para a instauração $e \quad o$ desenvolvimento das festas: graças a elas, conciliam-se os favores do povo que, quando dos sacrifícios, tem a sua parte dos animais imolados, e encontra prazer na beleza dos cortejos e dos espetáculos; sem dúvida ele não é insensível ao esplendor que [...] essas festividades conferiam a Atenas, e se felicita por essa ocasião que ela encontra de manifestar o seu poderio. (MEIER, 2004: 61)

Assim as festas dionisíacas conciliavam problemas internos, contribuindo para a coesão do corpo cívico. Cabe lembrar que os Pisistrátidas (Hiparco e Hípias, 527-514 a.C.) multiplicaram durante seu regime essas manifestações festivas (MEIER, 2004: 60). Meier apresenta-nos o seguinte quadro para compreendermos o elemento agregador das festas: 
As Grandes Dionisíacas começam pelo retorno solene da velha estátua de madeira do deus, que foi levada previamente para um bosque sagrado fora da cidade; elas prosseguem com uma brilhante procissão, para a qual cada uma das cidades da Confederação deve enviar um grande falo de madeira. Depois há os sacrifícios, em que abundam a carne e o vinho; após, desfila um cortejo alegre e turbulento. (MEIER, 2004: 70)

A pólis então se congregava para o espetáculo trágico. As tragédias eram apresentadas em três dias - em cada um deles se apresentavam três tragédias e um drama satírico de um mesmo poeta. $\mathrm{O}$ quarto dia era dedicado às comédias. As peças eram escolhidas mediante um concurso dirigido pelo Arconte Epônimo, o qual era responsável também por escolher os atores e recrutar os membros (coreutos) dos três coros, que seriam dirigidos e sustentados pelo chefe do coro, o corifeu, o qual tinha um grande prestígio político e compartilhava da glória do poeta em caso de vitória da tragédia em que participava.

O concurso trágico revela um outro aspecto da tragédia como elemento agregador da comunidade ateniense, por meio do seu apelo à competitividade, tão característica da cultura grega. John Gould ressalta a analogia com as grandes competições do mundo grego, as Olimpíadas e os Jogos Píticos realizados em Delfos:

Em ambas, a competitividade endêmica e potencialmente divisora da sociedade grega antiga era validada e santificada através da dedicação ao culto dos deuses de conspícuas mostras de feitos competitivos. As performances dramáticas de Atenas, como os concursos atléticos, extraíam muito do seu significado para aqueles que a assistiam do fato de serem competições de feitos perante os olhos da comunidade. Dramaturgos, atores e choregoi (atenienses que exibiam a sua fortuna pagando sumptuosamente pelos custos da performance) estavam todos tomando parte em uma competição uns com os outros e as vitórias de cada um eram tanto proclamadas publicamente e atestadas nos registros da pólis ateniense quanto em conspicuos monumentos privados." (GOULD, 2001: 177)

Assim, a competitividade, mediada pelo público e pelo culto aos deuses, administrava as tensões internas da pólis e se convertia em um elemento agregador marcado pela festividade e pela distribuição do mérito.

Faz-se necessário lembrar a advertência de Nicole Loraux: destacar os aspectos cívicos e políticos da tragédia não pode significar a identificação do teatro com a assembléia. Loraux ressalta a diferente relação com as paixões:

O teatro não é assembléia, embora sejam os mesmos homens que ocupem as arquibancadas da Pnix e assistam as Grandes Dionisíacas, a tragédia libera 
por certo no espectador paixões às quais o cidadão digno desse nome não poderia abandonar-se, mas ela os liberta, por assim dizer, sob controle, autorizando qualquer um a imergir no humano apenas pelo instante limitado de um parêntese institucional. (LORAUX, 1997: 29)

Com relação ao coro, cabe também notar que ele se distingue inicialmente dos outros personagens por seu caráter de grupo e a sua unidade é mantida por uma voz coletiva que canta de forma uníssona uma reflexão compartilhada pelo grupo. A personagem do coro em alguns momentos pode simbolizar a própria cidade, ou uma faceta da mesma. Para Battezzato, a importância do coro reside na sua marginalidade com relação à ação da peça e na sua distância com relação aos heróis no palco, que seriam registradas na própria estrutura dos seus diálogos líricos: "os membros do coro oferecem uma resposta para parte do texto que é ela mesma uma parte do texto. Desta forma eles são 'leitores/espectadores empíricos' localizados no interior do texto. [...] Os membros do coro 'lêem' a ação, mas eles oferecem dela uma reação empírica, não ideal. De fato a sua reação é tanto menos correta e mais profunda do que aquela de um espectador ideal." (BATTEZZATO, 2005: 154) Esta interpretação pode ser aproximada daquela de John Gould acerca do papel que o coro pode desempenhar no desenvolvimento e na construção do significado trágico na peça, criando relações de alteridade com o público. Ao passo que os personagens heróicos possuem um nome que é central à sua identidade, o coro, apesar de articular a experiência:

em termos de "eu" muito mais freqüentemente do que como "nós", o fazem sem ter um nome. O seu "eu” é uma primeira pessoa coletiva, não a voz de um indivíduo definindo o seu auto-entendimento em termos de diferença. Eles têm apenas uma identidade coletiva e um "nome" coletivo, se é que podemos chamá-lo assim. Este "nome" é usualmente derivativo, normalmente de um lugar (Persas, Mulheres da Tráquia, Mulheres Troianas), de um papel (suplicantes, bacantes), ou de uma linhagem coletiva (Danaides, Nereidas). Eles têm também uma memória "social" coletiva. As suas vozes múltiplas dão assim em sua canção uma expressão unívoca à sua consciência de grupo e à experiência e memória daquele grupo. (GOULD, 2001: 386-7)

Assim, o papel do coro estava ligado à expressão de uma experiência coletiva oposta à experiência singular do herói trágico.

Para Vernant, a institucionalização da tragédia com o concurso, com a figura do arconte, com o corifeu e o coro fazia com que a cidade se tomasse como objeto de 
representação e se desempenhasse a si própria diante do público (VERNANT; VIDALNAQUET, 1999: 10).

\section{Tragédia e mito}

A tragédia está intimamente ligada à ascensão da polis, a qual marcou a crise do sistema arcaico de construção da verdade. Como desenvolveu Marcel Detienne, a verdade na Grécia arcaica só era possível dentro de um sistema de representações religiosas: o discurso estava ligado ao sagrado e a verdade era privilégio do poeta, do adivinho e do rei da justiça (DETIENNE, 2006). Já a pólis marca a conquista do lógos como ferramenta política e uma nova relação com a verdade. A decisão na assembléia ou o discurso na ágora estão relacionados com um bom orador —a Peithó, divindade da persuasão, passa a ser cada vez mais lembrada pelos cidadãos.

Assim, para compreendermos a questão dos antecedentes do texto trágico, devemos atentar para o que Vernant chama de contexto mental, ou seja, um universo humano de significações homólogo ao próprio texto, um conjunto de instrumentos verbais e intelectuais, categorias de pensamento e um sistema de representações (VERNANT; VIDAL-NAQUET, 1999: 08). Neste contexto mental específico da tragédia grega se destacaria o pensamento social da cidade e o pensamento jurídico. No que concerne ao pensamento jurídico é necessário pensar que os gregos não possuíam uma ideia de um direito absoluto, com códigos e leis estabelecidos, mas potências sagradas ligadas à justiça e à ordem. Configura-se na tragédia um mundo de dualidade de justiça, de visões contrárias de mundo e de cidade que se embatem constantemente. Segundo Vernant, os poetas expandem essa dualidade para o vocabulário da tragédia:

Os poetas trágicos utilizaram esse vocabulário do direito jogando deliberadamente com suas incertezas, com suas flutuações, com sua falta de acabamento: imprecisão de termos, mudanças de sentido, incoerências e oposições que revelam discordância no próprio seio do pensamento jurídico, traduzem igualmente seus conflitos com uma tradição religiosa, com uma reflexão moral de que o direito já se distinguira, mas cujos domínios não estão claramente delimitados em relação ao dele. (VERNANT; VIDAL-NAQUET, 1999: 03)

Nesse sentido, as personagens da tragédia estão plenas de contradições que refletem a 
condição jurídica e política da tragédia. Nesse universo de significados altamente ambíguo criado por discursos multifacetados, os personagens constroem um pequeno espaço de consenso e uma grande área de conflitos. Tal descompasso na comunicação é um elemento essencial para o efeito trágico, para construção do mundo de ação dos personagens:

As palavras trocadas no espaço cênico têm, portanto, menos a função de estabelecer a comunicação entre as diversas personagens que a de marcar os bloqueios, as barreiras, a impermeabilidade dos espíritos, a de discernir os pontos de conflito. Para cada protagonista, fechado no universo que lhe é próprio, o vocabulário utilizado permanece em grande parte opaco; ele tem um único sentido. Contra essa unilateralidade se choca violentamente uma outra unilateralidade. (VERNANT, VIDAL-NAQUET, 1999: 19-20)

Se o próprio diálogo da tragédia carrega esses elementos de incomunicabilidade, a ação dos personagens se revela turva e confusa aos seus próprios olhos. Vernant destaca que o agir tem um duplo caráter, de deliberar consigo mesmo analisando prós e contras e organizando os meios e os fins e de contar com o desconhecido (VERNANT; VIDALNAQUET, 1999: 21).

Outro elemento importante para compreender os antecedentes da tragédia, como já mencionado, é a relação que o texto trágico mantém com o mito. A tragédia reinterpreta o mito, revestindo-o com um problema ou conflito vivido na cidade pelos cidadãos. De acordo com Loraux, os mitos desempenham um papel importante para a coletividade, para esta identidade cívica que o espetáculo trágico congrega:

O mito desempenha o seu papel na pólis, face a ela mesma, face às outras poleis. Ele adquire na pólis uma história, [...] uma história no entanto que não é sem interferências com aquela, política, social, ideológica, da coletividade. Ele torna-se aí, sobretudo, porque ele contém um discurso à cidade e para a cidade, uma das vozes interiores do imaginário político: sempre já presentes mas também sempre reatualizados, os esquemas míticos legitimam e modelam a experiência cívica. A pólis utiliza-os, mas talvez também cedesse à persuasão dos seus ditos muito antigos. (LORAUX, 1990: 35)

Já Charles Segal defende que o distanciamento do mito nas tragédias tornou possível novas sensibilidades dentro da sociedade grega:

Na tragédia, a organização do material narrativo dos mitos por um texto escrito torna possível um relato visual de um poder novo e mistura voz e visão em relações novas e complexas. Graças a esta mudança de ênfase, as metáforas do espetáculo ou do teatro podem descrever a experiência 
humana em geral. (SEGAL, 2000: 304)

O texto trágico marca um grande momento na história do pensamento ocidental pois ele é a demonstração de um distanciamento em relação ao mito. A inspiração para os poetas trágicos era a grande tradição de textos e relatos que contavam as histórias dos deuses e heróis, sendo que a maioria destas histórias está presente nas épicas de Homero. Os autores das tragédias reinterpretavam o mito e revestiam-no de uma originalidade marcada pelo momento da pólis e pela autoria de cada poeta. Assim, quando os cidadãos assistiam a Édipo Tirano de Sófocles, eles não se surpreendiam com o incesto ou com o parricídio do herói, pois eram elementos já conhecidos do mito, mas sim com questões da sabedoria do governante e os modos de agir frente aos problemas . Os heróis míticos como Odisseu são problematizados, assumindo posições ambíguas e se distanciando de antigas representações religiosas.

\section{Sentidos políticos do texto trágico}

Para entender o caráter cívico da tragédia, a qual dialoga com as instituições sociais da pólis, a partir da máxima de Meier que trata o espetáculo trágico como uma arte política, é preciso atentar resumidamente para como era compreendida a ação política pelos gregos e também para dois momentos da história de Atenas -a isonomia de Clístenes e o apogeu da democracia pericleana- que ajudam a entender a singularidade da identidade do cidadão ateniense.

Os gregos chamavam de política aquilo que era próprio da pólis. Nesta definição específica, política refere-se à cidade como um conjunto de cidadãos que a constitui e fundamenta. Meier defende que a política para os gregos pode ser compreendida como um "campo de ação", delimitado por uma constituição, colocado dentro de uma esfera que alcançava e congregava todos os cidadãos (politéia). Principalmente no século V a.C., a política fundamentava-se primeiramente em uma noção de unidade: desta unidade enraizada na comunidade de cidadãos emergia a autoridade política (MEIER, 1996: 34).

As reformas de Clístenes (508 a.C.) foram basilares na construção deste campo de ação, pois possibilitaram o engajamento e a mobilização. Clístenes dividiu os atenienses em dez tribos, no lugar das quatro anteriores - este aumento visava que mais pessoas pudessem 
participar da politéia. Além disso, ele dividiu cada uma destas dez tribos em três partes chamadas de Trítias, uma no litoral, uma na cidade e arredores e uma no interior, atribuindo por sorteio um representante para cada trítia- ou seja, três representantes para cada tribo. A criação das Trítias buscava evitar o desenvolvimento de alianças regionais. Clístenes também aumentou a Boulé de quatrocentos para quinhentos membros, pois cada uma das então dez tribos designava cinquenta representantes para a Boulé. Assim, toda a organização das instituições cívicas e do calendário foi determinada pelo sistema das dez tribos. Claude Mossé acredita que esta divisão podia ser uma influência do espírito geométrico e da filosofia jônica (MOSSÉ, 1982: 22).

A principal novidade inserida pelas reformas de Clístenes para o campo de ação defendido por Meier é a noção de isonomia, de que todos os cidadãos eram iguais em direitos perante a lei. A isonomia permitia que os cidadãos, independentemente do critério de renda, pudessem interferir regularmente na política. Mossé afirma que "é esta isonomia que traduz concretamente a reforma de espaço cívico e, mais simplesmente, o fato de que, doravante, um ateniense não mais se nomearia pelo nome do pai, mas pelo seu demès de origem.” (MOSSÉ, 1982: 23).

Vernant acredita que a isonomia é uma herança de uma tradição igualitária antiga no pensamento grego, que pode ser vista inclusive nas épicas de Homero. De acordo com o helenista francês, "vários testemunhos mostram que os termos isonomia, isocracia serviram, em círculos aristocráticos, para definir, por oposição ao poder absoluto de um só [...], um regime oligárquico em que a arché é reservada a um pequeno número, excetuando-se a massa, mas é partilhada de maneira igual entre todos os membros dessa elite." (VERNANT, 2004: 65-66)

As mudanças de Clístenes, além de moldar as origens da democracia, geraram uma transformação que unificou os cidadãos, criando uma identidade cívica enraizada na participação. Nesse contexto se forma um pensamento político independente, que não é ligado a tendências particulares, mas aos interesses da pólis. Meier apresenta as mudanças ocorridas com a isonomia da seguinte forma:

É assim que a isonomia se torna a palavra de ordem; e daí se apreende uma grande força mobilizadora. Como a vida cívica ganha uma importância tão

\footnotetext{
Em Tempo de Histórias

Publicação do Programa de Pós-Graduação em História da Universidade de Brasília (PPGHIS/UnB)

No. 23, Brasília, ago. - dez. 2013 ISSN 2316-1191
} 
pouco comum, é em relação a ela, antes de tudo, que se determina o status, o valor de um homem. Há poucas possibilidades sérias de fazer fortuna; na atividade econômica, setores inteiros marcados pelo descrédito. É só na política que alguém pode melhorar o seu estado, é aí que se abre para muitas pessoas uma chance de ascender. (MEIER, 2004: 26)

Neste contexto, forma-se um campo de ação que possibilita não só a participação efetiva nos assuntos da cidade, mas a possibilidade de desenvolvimento de outra esfera, na qual a igualdade de responsabilidades permite interagir além do mundo privado e religioso. Desenvolvem-se novas concepções e dinâmicas de compreensão do mundo, entre elas um tipo específico de solidariedade entre os cidadãos, como descrito por Meier:

Uma tal identificação da coisa pública com a comunidade dos cidadãos pressupunha uma solidaridade particular, a qual, para além das divergências dos interesses particulares, devia enraizar-se em um interesse geral da comunidade. Este interesse tornou-se tão predominante que, neste novo domínio da vida pública, os cidadãos determinavam a política tanto quanto ela os determinava. Outros interesses ficaram, por outro lado, ou relativamente negligenciados, ou mantidos, em grande medida, distantes do campo político. Para politizar a si mesmos, os cidadãos não podiam então politizar os seus interesses particulares. (MEIER, 1996: 35)

Tal qual Meier, Vernant defende que o ideal de isonomia transformou radicalmente a ordem dentro da pólis. Segundo ele, a ideia de igualdade permitira aos cidadãos tomarem-se como idênticos apesar das diferenças sociais, mantendo relações simétricas de reciprocidade (VERNANT, 2004: 107). A pólis associada à ideia de simetria construía assim um universo homogêneo, sem hierarquia, sem planos diversos.

Contudo, por mais que a isonomia e posteriormente os anos dourados da democracia de Péricles tornassem a política um campo de ação denso e ativo, é preciso ter cuidado com idealizações em relação ao cidadão grego. Para um grande grupo de cidadãos, a política era apenas uma esfera do mundo concreto que ultrapassava as relações da esfera privada, das trocas parentais e de vizinhança (MEIER, 1984: 14).

Outro momento importante para a compreensão da identidade política ateniense, tão significativa para a visão do texto trágico aqui defendida, é a democracia pericleana. A época de Péricles é descrita como a era de ouro de Atenas, e teria o seu apogeu entre as Guerras Médicas (499-449 a.C.) e a Guerra do Peloponeso (431-404 a.C.).

Para compreendermos a singularidade desta democracia, podemos recorrer a pequenos 
trechos da Oração Fúnebre que Tucídides atribuiu a Péricles no primeiro ano da Guerra do Peloponeso. Péricles reivindica na palavra democracia a principal característica de Atenas: "Nosso regime político (politéia) não se propõe tomar como modelo as leis de outros: antes somos modelo que imitadores. Como tudo nesse regime depende não de poucos, mas da maioria, seu nome é democracia." (Tucídides, II, 37, 2) De acordo com Mossé, a palavra democracia era relativamente recente no momento em que Péricles a usa no discurso. Ela também carrega consigo uma ambigüidade. O termo democracia é composto de duas palavras, dêmos e o verbo kratéin. Dêmos podia designar todo o conjunto dos cidadãos, sem distinções de nascimento e riqueza, ou podia designar apenas os cidadãos de menores posses. Assim, o regime chamado democracia tinha um sentido dúbio: seria um sistema político em que a soberania residia no conjunto do corpo cívico ou então um sistema em que a camada social mais baixa controlava a cidade. Péricles exalta as decisões que dependem da maioria (pleiôn), pois ela representaria a soberania do conjunto dos cidadãos.

Esta soberania do dêmos fundamentava-se nas assembléias, na participação popular das camadas mais baixas. Para ter sucesso nas assembléias era necessário ter um bom domínio das artes da persuasão - por isso, os sofistas foram fundamentais para a educação ateniense. Na continuação da Oração Fúnebre, Péricles complementa: “[Na democracia], enquanto no tocante às leis todos são iguais para a solução de suas divergências particulares, no que se refere à atribuição de honrarias o critério se baseia no mérito e não na categoria a que se pertence; inversamente, o fato de um homem ser pobre e de condição humilde não o impede de prestar serviço à cidade, desde que tenha capacidade para tanto.” (Tucídides, II, 37, 2) Neste trecho, são apresentadas outras duas características da democracia pericleana, a igualdade dos cidadãos perante a lei e o mérito, que substitui outras distinções.

O que permitia a participação efetiva dos cidadãos mais pobres era a mistoforia. De acordo com a Constituição de Atenas (XXVII), foi Péricles, em uma medida popular, quem estabeleceu o salário para os tribunais, principalmente para os membros da Boulé. De fato, a atribuição deste misthós (remuneração) possibilitava estar livre do trabalho cotidiano e dedicar-se ao tribunal, de forma que a mistoforia (c.454-450 a.C.), assim, possibilitava a efetivação da participação das camadas mais baixas (MOSSÉ, 1982: 37).

O princípio da igualdade perante a lei, ou seja, a isonomia, não pode ser pensado 
separadamente de um contexto de desigualdades sociais e de desigualdades políticas que eram constantemente combatidas pelo dêmos. A desigualdade política, como lembra Mossé, era limitada e combatida por meio de um jogo de força presente na democracia pericleana embora os mais pobres não pudessem subir às mais altas funções no controle da cidade, eles eram a maioria no dêmos, restabelecendo assim um equilíbrio. Quanto ao equilíbrio social, “ele era garantido não apenas pela mistoforia, mas também, e talvez sobretudo, pelos encargos financeiros que os mais ricos assumiam em nome da cidade e de que os mais pobres, em parte, se beneficiavam.” (MOSSÉ, 2008: 80)

Para compreender a relação entre texto trágico e a identidade política, é necessário também atentar para outro trecho da Oração Fúnebre em que Péricles diz: "temos concursos e festas religiosas durante todo o ano." (Tucídides, II, 38) Entre estes concursos e festas está a celebração das Grandes Dionisíacas. Neste momento é preciso retomar a tragédia no seu papel de coesão do corpo cívico para estabelecer o seu viés identitário.

A identidade de uma sociedade está fundamentada em diversos aspectos da realidade; ela é constituída na medida em que os membros de uma sociedade partilham e constroem sensibilidades comuns. No caso dos cidadãos atenienses do século V a.C., a política era força central para a definição dessas sensibilidades formadoras da identidade. O espetáculo trágico como produção cultural de dimensões religiosas em sua origem e caráter cívico e congregador para os cidadãos atenienses não deixa de compartilhar deste viés político, formador da identidade do cidadão. A tragédia, como exposto anteriormente, possui dia, lugar e público específico e como instituição cultural própria da cidade colocava em perspectiva problemas próprios da cidade.

Assim, a arte política constitui-se no texto trágico à medida que o poeta constrói o texto em discussão com a identidade da pólis, aproximando os personagens do drama das discussões que permeiam a cidade. Como nos aponta Meier:

a experiência e a problemática política podiam então justamente determinar uma nova interpretação do mito. Os problemas da atualidade podiam então ser abordados, de maneira mais ou menos direta, e o mito era ilustração deles. É nestes momentos que a tragédia reflete para nós um aspecto do pensamento político da época; ela exerce então verdadeiramente a sua função educativa essencial: instância globalmente neutra, ela atualiza os problema ou as realizações da pólis; traz à consciência a essência mesma 
do político e exprime talvez certas advertências de ordem geral. (MEIER, 1996: 144)

Meier discute desta forma a velha máxima do filólogo Walter Nestle, tão citada e difundida por Vernant e por Vidal-Naquet, de que a "tragédia nasce quando se começa a ver o mito com o olhar do cidadão." (VERNANT; VIDAL-NAQUET, 1999: 10)

\section{Considerações finais}

Assim, o espetáculo trágico constitui-se em uma arte política por colocar problemas de ordem cívica e questionar os limites da ação humana através de temas como poder, tradição e sabedoria. A apropriação do mito revestida pela originalidade de cada autor colocou nos textos trágicos uma capacidade de reflexão sobre os problemas da pólis ainda não conhecida no mundo grego. O espetáculo do teatro na Grécia colocava a pólis em momento de congregação para a reflexão acerca de problemas internos à cidade. $O$ teatro faz-se política na Grécia Antiga à medida em que os problemas colocados em cena pelas tragédias transcendem o mito e discutem as ações dos cidadãos e os limites da ação humana frente ao poder.

\section{Referências}

ARISTÓTELES. Poética. Tradução de Eudoro de Sousa. Edição bilíngue grego-português. São Paulo: Ars Poética, 1993.

BARTHES, Roland. "Pouvoir de la tragédie antique." In: . Écrits sur le théâtre. Paris: Éd. du Seuil, 2002.

BATTEZZATO, Luigi. "Lyric.” In: GREGORY, Justina (ed.). A companion to Greek tragedy. S/l: Blackwell Publishing, 2005, p. 149-166.

CUSSET, Christophe. La tragédie grecque. Paris: Éd. du Seuil, 1997.

DETIENNE, Marcel. Les maîtres de vérité dans la Grèce Archaïque. Paris: Librairie Générale Française, 2006.

GOULD, J. Myth, ritual, memory and exchange. Oxford: OUP, 2001.

LORAUX, Nicole. Les enfants d'Athéna: idées athéniennes sur la citoyenneté et la division des sexes. Paris: La Découverte, 1990. 1997, p. $17-34$

“A tragédia grega e o humano." In: NOVAES, Adauto (org.). Ética. São Paulo: Companhia das Letras, 
MEIER, Christian. Introduction a l'anthropologie politique de l'antiquité classique. Paris: PUF, 1984. La naissance du politique. Paris: Gallimard, 1996. De la tragédie grecque comme art politique. Paris: Les Belles Lettres, 2004.

MOSSÉ, Claude. Atenas: a história de uma democracia. Brasília: Ed. Universidade de Brasília, 1982, 142pp. Péricles: o inventor da democracia. São Paulo: Estação Liberdade, 2008.

SEGAL, Charles. "L'homme grec, spectateur et auditeur." In: VERNANT, Jean-Pierre. L'homme grec. Paris: Éd. du Seuil, 2000.

TRABULSI, J.A. Dabdab. Dionisismo, poder e sociedade na Grécia até o fim da época clássica. Belo Horizonte: Ed. UFMG, 2004.

VERNANT, Jean-Pìerre. As origens do pensamento grego. Rio de Janeiro: Difel, 2004.

VERNANT, Jean-Pierre; VIDAL-NAQUET, Pierre. Mito e tragédia na Grécia Antiga. São Paulo: Perspectiva, 1999. 
